\title{
POSITIONING HISTORICAL TRAUMA THEORY WITHIN AOTEAROA \\ NEW ZEALAND
}

\author{
Leonie Pihama* \\ Paul Reynolds ${ }^{\dagger}$ \\ Cherryl Smith ${ }^{\ddagger}$ \\ John Reid $\$$ \\ Linda Tubiwai Smith" \\ Ribi Te Nana ${ }^{\#}$
}

\begin{abstract}
This article explores the relevance of historical trauma theory for Māori research. In exploring the impact of historical trauma upon Māori it has become clear that the terminology associated with historical trauma theory is considered controversial in Aotearoa New Zealand. As such, this article provides an overview of key definitions relevant to historical trauma and explores these in relation to recent reporting related to the use of the terms "holocaust" and "genocide" in the context of colonization in Aotearoa New Zealand. It is argued that in order to engage fully with the impacts of colonization on Māori wellbeing we must articulate fully the impact of historical trauma events and the contribution of those events to the negative health disparities experienced by many of our whānau (extended family), hapū (sub-tribes) and iwi (tribes).
\end{abstract}

* Director, Māori and Indigenous Analysis, Associate Professor, Te Kotahi Research Institute, Hamilton, New Zealand.

Email: leonie@maia.maori.nz

† Director, Te Atawhai o te Ao: Māori Institute for Environment and Health, Whanganui.

‡ Director, Te Atawhai o te Ao: Māori Institute for Environment and Health, Whanganui.

§ Senior Researcher, Te Rūnanga o Ngāi Tahu, Christchurch, New Zealand.

" ProVice Chancellor Māori, University of Waikato, Hamilton, New Zealand.

\# Researcher, Kakariki Ltd., Auckland, New Zealand. 


\section{Keywords}

historical trauma theory, kaupapa Māori, genocide

\section{Introduction}

He kokonga Whare e kitea, he kokonga ngākau kāhore e kitea.

The corners of a house are visible; the corners of the heart are invisible.

—whakataukī (proverb)

Over the past 10 years there has been a growth in the use of historical trauma theory in Aotearoa New Zealand (hereafter referred to as New Zealand). This has been influenced by Native American scholars such as Bonnie Duran, Karina Walters and Eduardo Duran who provided a number of keynote presentations at Māori conferences and symposia held by organizations such as Te Atawhai o te Ao (Independent Māori Research Institute for Environment and Health) and Ngā Pae o te Māramatanga (Centre of Research Excellence which conducts research of relevance to Māori communities) which have led to critical conversations about the impact of historical traumatic events on our lives, and our understanding of ourselves within a context where colonization has interrupted and disrupted the intergenerational transmission of tikanga (protocols), reo (language) and mātauranga Māori (Māori knowledge). This article discusses the significance of historical trauma theory for Māori research that engages the impact of colonization on whānau (extended family), hapū (sub-tribes) and iwi (tribes).

The phrase "historical trauma" was coined in relation to providing an analysis and framework for understanding the traumatic experiences of holocaust survivors and the subsequent impact of those experiences on following generations
(Brave Heart, 2000; Evans-Campbell, 2008). It has also been used in discussion of the intergenerational impact of Japanese concentration camps during WWII (Drinnon, 1987; Howard, 2008; Nagata, 1991). Brave Heart and DeBruyn (1998) argue that holocaust survivor literature provides analysis and applied knowledge that informs historical trauma theory for Native communities.

It is powerfully argued by Native scholars that as a result of genocidal and ethnocidal acts perpetuated against Native peoples they experience intergenerational transfer of trauma similar to that of descendants of holocaust survivors (Brave Heart \& DeBruyn, 1998; Duran \& Duran, 1995). Duran and Duran (1995) highlight the intergenerational impact as a direct outcome of unresolved trauma which manifests in a range of dysfunctional behaviours that then inform the learning environment of, and are passed on to, subsequent generations.

It has been evidenced that Native people experience higher rates of personal trauma than white Americans, and suffer a higher prevalence of lifetime trauma, abuse, interpersonal violence, substance abuse, lower educational success, depression and post-traumatic stress disorder (PTSD) (Balsam, Huang, Fieland, Simoni, \& Walters, 2004; Brave Heart, 1999; Walters, Simoni, \& Evans-Campbell, 2002). It is also documented that a range of stressors that derive from experiences and transmission of historical trauma are implicated in not only mental health issues but also physical illness (Estrada, 2009; Walters, 2007; Walters et al., 2002).

Brave Heart (1999) locates social issues rising from historical trauma within the construct of oppression and the "unresolved grief across generations" (p. 60). Brave Heart describes a key element of historical trauma-“historical 
disenfranchised grief"-which relates to unresolved grief; that is, denied, unacknowledged and un-mourned grief (p. 60). In identifying the centrality of "disenfranchised grief”, Brave Heart provides insightful understandings of the ways in which historical trauma manifests itself through generations and impacts in multiple ways upon the lives of many Indigenous peoples. Brave Heart argues "the concept of disenfranchised grief facilitates the explanation of historical unresolved grief among American Indians" (p. 67). This analysis highlights that the denial of cultural grieving for those deaths caused by historical trauma events results in intergenerational unresolved grief. That grief impacts significantly on the wellbeing of Native peoples and has critical implications for following generations. These understandings resonate for kaupapa Māori (Māori philosophy) theorists who argue that whakapapa (genealogy) is essential to the transformation of Māori knowledge not only in material terms but also in regards to spiritual relationships (Pihama, 2001; Taki, 1996).

What is particularly significant in the work of Maria Yellow Horse Brave Heart (2000; Brave Heart \& DeBruyn, 1998) is that it is grounded within the collective experiences of her people. Such a positioning is critical as it is a project that explores both historical and intergenerational trauma, and, we would argue, is central to a kaupapa Māori approach to wellbeing. In locating her work, Brave Heart (2000) emphasizes her own positioning as a Lakota woman and her relationship with and understanding of historical trauma through the history of her own people.

The articulation of historical trauma theory from a Native American perspective has been critical in the development of systems of healing that both acknowledge and respond to the impact of colonization and colonial acts of genocide upon Native peoples over the past 500 years. Early developments in the area included writings by Maria Yellow Horse Brave Heart (Brave Heart \& DeBruyn, 1998), and Bonnie
Duran and Edwardo Duran (1995), with their early work being drawn upon in developing both understandings and healing within a wide range of Native American communities and a fundamental challenge to the inadequacies of Western psychological frameworks to contextualize Native American experiences of colonialism. Native American peoples have experienced traumatic and genocidal events for over 500 years and the effects of such systemic acts are devastating for communities both in their direct impact and in how they are understood (Duran \& Duran, 1995).

The effects of the genocide are quickly personalized and pathologized by our profession via the diagnosing and labeling tools designed for this purpose. If the labeling and diagnosing process is to have any historical truth, it should incorporate a diagnostic category that reflects the impacts of genocide. Such a diagnosis would be "acute and or chronic reaction to colonialism". In this sense, diagnostic policy imposes a structure of normality based in part in the belief in the moral legitimacy and universality of state institutions. The generation of healing knowledge from the land of the colonist-as has been the history of crosscultural work-will no longer suffice. (p. 6)

Key elements of historical trauma identified include the collective intergenerational wounding as a result of "massive cataclysmic events" and that historical trauma is experienced personally and transmitted through generations and therefore descendants of those who experience the trauma feel the effects (Walters, 2007). Walters highlights the multiple ways in which the concept of historical trauma is viewed and defined:

When I am talking about historical trauma I am talking about massive cataclysmic events that target a collective. I am not talking about single event discriminatory experiences that's between one or two people but a whole group 
of people or community that is targeted. In our communities we talk about how this trauma is transmitted over generations so I may not have experienced the Trail of Tears, my great grandparents did so therefore what aspects of that trauma do I still carry in my history to this day .... One of the things that's really hard to distinguish around historical trauma research is how we think about historical trauma as a factor. Some people talk about historical trauma as an ideological factor, as a causal factor, so we look at things like historically traumatic events causing poor health outcomes. Other folks talk about historical trauma itself as an actual outcome in terms of things like historical trauma response or a Native specific way of manifesting what I call colonial trauma response and I will talk a bit more about that, historical trauma can also be conceptualized as a mechanism or a pathway by which trauma is transmitted. (Walters, 2007, n.p.)

Duran (2006) notes that those working in the area must be aware of the "horrendous holocaust” experienced by Native people (p. 7). Central to these understandings is an acknowledgement of the enormity of the acts of genocide by colonial invaders to Great Turtle Island. Evans-Campbell (2008) also emphasizes the need for a deep understanding of the magnitude of the impact of historical trauma and the intentional acts of genocide and ethnocide that drive such events.

The place of intergenerational transmission of trauma within historical trauma theory is critical as it has been argued that a lack of knowledge of the impact of the multigenerational aspects of trauma has meant that impact on the descendants of survivors of historical trauma has remained "misunderstood and not treated appropriately" (Brave Heart, 2000). Historical trauma is understood as:

cumulative emotional and psychological wounding, over the lifespan and across generations, emanating from massive group trauma experiences. (Yellow Horse \& Brave Heart, 2005, p. 58)

Duran and Duran (1995) also discuss wounding through the concept of the "soul wound". The "soul wound" sits at the core of generations of Indigenous suffering and is a central element in understanding historical trauma. Duran (2006) speaks of the concept of the soul wound being expressed by Native communities. He writes that within the Native community, people talked of issues within the community in relation to "spiritual injury, soul sickness, soul wounding and ancestral hurt" (p. 15). Clearly each of these concepts links directly to the notion of historical trauma and emphasizes the impact on a spiritual and soul level. As such, discussions of "soul wounding" within Native communities challenged some of the fundamental understandings or misunderstandings of Western psychology, as Duran writes he was unable to find any reference to "soul wounding" or even the "soul" in psychological literature at the time. The "soul wound" is a process and outcome of historical trauma. Duran (2006) provides insight into how Native elders related the significance of the soul wounding practice. He writes:

They explained that the ancestral wounding that occurred in the community was being passed down through the generations. They gave accounts of how the genocide had occurred in their area. Between the years 1870 and 1900 , at least $80 \%$ of the population had been systematically exterminated. In addition, they explained how the earth had been wounded and how, when the earth is wounded, the people who are caretakers of the earth also are wounded at a very deep soul level. Earth wounding speaks to the process whereby people become destructive to the natural environment and disturb the natural order. (p. 16)

Historical trauma is collective, cumulative wounding both on an emotional and 
psychological level that impacts across a lifetime and through generations, which derives from cataclysmic, massive collective traumatic events, and the unresolved grief impacts both personally and intergenerationally (Brave Heart, 1999, 2000; Brave Heart \& DeBruyn, 1998).

\section{Historical trauma events}

A key element to historical trauma theory and practice is that of identifying the historical traumatic events experienced. Within the area of trauma testimony discussed by Brave Heart (1999; Brave Heart \& DeBruyn, 1998), a range of historical traumatic events was discussed alongside the impact of those events. Acts of genocide such as that perpetuated in the Wounded Knee Massacre were recounted by participants, as were the removal of Lakota children to boarding schools and the physical and sexual abuse experienced by generations of Lakota families; the subsequent impact of those experiences on descendants of boarding school survivors; and the ongoing racism that Lakota children faced within day school experiences. Giving testimony to those genocidal and ethnocidal events is critical for Indigenous peoples.

Tessa Evans-Campbell (2008) argues that whilst Native communities have shown a strength and resilience in light of colonization and associated historical trauma, there has been a huge toll experienced. It is argued that standard diagnosis in relation to trauma and the impact of historical trauma is limited in regards to Native American and Alaskan communities (Evans-Campbell, 2008). Marie-Anik Gagne (1998) notes that colonialism is a traumatic act and defines trauma as a shock that creates substantial emotional and psychological damage which often manifests in forms of neurosis.

Gagne (1998) highlights that the effects of trauma on First Nations people have been primarily discussed in terms of PTSD with the definitions of PTSD being framed within the
Diagnostic and Statistical Manual of Mental Disorders (DSM-III-R and DSM-IV), with PTSD being classified under anxiety disorders. However, it has been argued for some time that the DSM-IV has major limitations in regards to the impact of historical trauma experienced by Native peoples and that standard PTSD nomenclature "fails to adequately represent" Native American experiences of trauma (Brave Heart, 1999, p. 3). Gagne (1998) further argues that whilst colonialism is often viewed as the "primary source of problems faced by First Nations citizens" (p. 358) it is rarely discussed in PTSD research, and, in particular, few studying in the field engage specific historical events and the impact on First Nations communities. It is clear that engaging with specific historical events and experiences is critical.

Evans-Campbell (2008) highlights the importance of differentiating between every day or regular life stressors and traumatic events. Regular life stressors are seen as those things that are an expected part of life; traumatic events are outside those expectations. EvansCampbell (2008) lists clear limitations of PTSD classifications, highlighting that they (i) were not developed to address intergenerational trauma; (ii) are inadequate in relation to the possible compounding nature of responses to multiple stressors; (iii) focus only on impacts upon the individual and not upon social or familial impacts; (iv) do not explore how historical and contemporary traumas interact; (v) do not explore how present trauma can be understood in relation to historical events; and (vi) are limited in regards to exploring facts that buffer the impact of such trauma.

Duran and Duran (1995) highlight specific periods within which traumatic events occurred for Native peoples that have impacted directly in terms of intergenerational PTSD. The periods noted are:

- First Contact: Initial contact between Native peoples and colonizers where the "lifeworld" of Indigenous peoples was 
threatened and systematically destroyed. Loss and separation, both from each other and from a way of life, dominated and losses were not given a grieving process.

- Economic Competition: Land, wildlife and all forms of sustenance were destroyed or confiscated by the colonizers. The philosophies and practices of the relationship of all living things and "oneness and harmony with the environment" (p. 33) held by Native peoples was undermined and a new economic ideology imposed.

- Invasion War: A policy of genocide by the United States Government became dominant with many Native people murdered or removed from their homelands and displaced.

- Subjugation and Reservation: The removal of Native people from their territories and forced relocation on to reservations, destroying connections to traditional lands and undermining cultural ways through forcing people on to unfamiliar territories.

- Boarding School: The destruction of the family unit, "designed to destroy the fabric of Native American life" (p. 33). The forced removal of Native children, the denial of their language and culture.

- Forced Relocation and Termination: Further termination of Native peoples through forced relocation into large urban centres, and intensification of the impact of refugee and concentration camp syndromes (pp. 32-34).

Whilst there is a wide variation of events that are associated with historical trauma, EvansCampbell (2008) identifies three distinguishing features or characteristics.

1. They are widespread within American Indian and Alaska Native (AIAN) communities and many people within the community are impacted upon or affected by the event.

2. They generate high levels of collective distress and mourning in contemporary communities.

3 . They are generally purposely perpetuated by outsiders with destructive intent. (p. 322)

Walters, Beltran, Huh, and Evans-Campbell (2011) note that the "devastating high rates of health disparities" for Native peoples are linked to historical trauma events such as the confiscations and dispossession of land and forced relocation. They argue that Native academics are turning to examine the role of "place-based historically traumatic events (e.g. forced relocation and land loss), [and] environmental microaggressions (discrimination distress based on land desecration)" (p. 166) and highlight that such exposures are hazards to Native health and can persist for generations. The relationship of land/place and wellbeing is articulated as follows:

For Indigenous People, disease or literally dis-ease (out of balance, disharmony, disequilibrium) is tied to the holistic understanding of the interconnectedness of mind, body, emotion, spirit, and land. Indigenous knowledge recognizes place as integral to one's sense of being which is also central to both individual and collective spiritual health and wellness. Conversely, for Indigenous People, loss of place (i.e. displacement) is akin to loss of spirit or identity. (p. 173)

The literature indicates that there are a range of historical events that contribute to Native peoples' experiences of historical trauma which impact in complex ways upon the cultural, spiritual, emotional and physical wellbeing of Indigenous peoples. Those impacts then culminate in a range of what are referred to as historical trauma responses, which are discussed in the next section. 


\section{Historical trauma response}

The work of Maria Yellow Horse Brave Heart provides for Indigenous peoples a model for understanding the potential impact of the collective historical traumatic experiences of our nations alongside contemporary or present day traumatic life experiences. What is clear is the need for Indigenous worldviews to define the ways in which such features are both defined and engaged. Brave Heart (2000) highlights that historical trauma responses-such as transposition, and identifying with the dead and the suffering of ancestors-must be viewed through a Lakota cultural view which recognizes and acknowledges the ways in which Lakota culture maintains relationships and means of acknowledging the spirit world.

An area identified as not being engaged fully within holocaust survivor research on historical trauma is that of the experiences of survivors and descendants in relation to coping. Brave Heart (1999, 2000) highlights that the emotional experiences of trauma place stress upon survivors which exacerbates both psychological and physical impacts.

Working within the Lakota community alongside "high functioning individuals" enabled the identification of coping skills and behaviours and strategies for "transcending trauma". She highlights features of historical trauma response for Lakota peoples as including:

1. transposition- "where one lives simultaneously in the past and the present with the ancestral suffering as the main organizing principal in one's life" (Brave Heart, 2000, p. 246);

2. identification with the dead to a point that in essence one feels dead or unworthy of living;

3. a loyalty and identification with the suffering of deceased ancestors and re-enacting such affliction in their own lives (Brave Heart, 2000, pp. 246-247).
These features, she notes, are also compounded by others such as "survivor guilt, an ensuing fixation to trauma, reparatory fantasies, and attempts to undo the tragedy of the past" (p. 247). Such features align to those highlighted by researchers working in the area of the impact of historical trauma on holocaust survivors and their families with the manifestation of such impacts upon the overall wellbeing having been documented by those in the field (Brave Heart, 2000; Evans-Campbell, 2008).

Literature highlights that amongst holocaust survivors and their descendants, and amongst Lakota people, the range of historical trauma responses observed include depression, psychic numbing, difficulty recognizing and expressing emotions, low self-esteem, poor affect tolerance, anger, elevated mortality rates from suicide and cardiovascular diseases, self-destructive behaviour, and may include substance abuse and self-medication (Brave Heart, 1999; Brave Heart \& DeBruyn, 1998).

It is argued that the generation of Native American people who face collective historical traumatic events suffer forms of PTSD, with subsequent generations experiencing the impact and also "historical unresolved grief", where those generations experience a "pervasive sense of pain" and an "incomplete mourning of those events". This becomes more complex with the oppressive nature within which present generations of Native peoples are located, and the high rates of current losses within Native communities from suicide, alcohol- and drug-related deaths, homicide, child abuse, domestic violence, and other forms of violence perpetrated upon communities and their members (Brave Heart \& DeBruyn, 1998, p. 70).

Responses to such oppressive acts and the legacy of historical trauma manifest in multiple ways that culminate in both personal and interpersonal responses, including trauma identity; carrying trauma; anger; impaired bonding; transposition; survivor guilt; suicidal ideation; multiple traumas; and somatic symptoms. Each of these responses was articulated directly in 
relation to the experiences of the traumatic acts perpetuated upon Lakota peoples. Lakota people spoke of the many levels of trauma responses that impacted upon them and their families, and upon past and future generations. Trauma responses shared are clearly intergenerational and the work to transcend such trauma was grounded in notions of healing and transformation, as Brave Heart writes:

Under the theme of transcending the trauma, healthy coping strategies used to deal with the trauma, ideas about healing, and transformation of the traumatic past were revealed. Coping strategies included emphasizing traditional Lakota values, focusing on helping others and future generations. Ideas about healing incorporate awareness of and talking about the past with a focus on the commonality among the Lakota of shared trauma. (Brave Heart \& DeBruyn, 1998, p. 260)

There is a growing body of research related to the embodiment of historical trauma and the impact on physical wellbeing. Mariana Ferreira (2004) notes that the sharing by Yurok elder Mollie Ruud of her incarceration at the Chemawa Boarding School for Indian Children in Oregon highlighted the connection of historical trauma to type 2 diabetes and that the narrative "unveils the intrinsic links between diabetes and oppression, pointing directly to the perverse ways in which colonialism and genocide have placed Indigenous peoples at heightened risk for the disorder" (p. 357). Ferreira argues that in spite of "more than a century" of research that highlights that diabetes originates in the nervous system, there has been a denial of the impact of emotional causes and instead the over-representation of Indigenous peoples with diabetes has been located within deficit and genetic explanations (p. 357). As such, the impact of oppression and historical trauma has been denied and reductionist science has dominated the field through its "search" for genetic causes. The emotional impact of struggling for Indigenous rights for her people is strongly voiced by Mollie Ruud, as is its physical impact.

Fish sure is a hot issue around here. People get all worked up when it comes to fishing rights and regulations on the reservation. My blood sugar always goes up just to think of it, especially after a fish meeting. And everyone is involved in this war, in one way or another. 'Cause it is a war, you know ... the feds are here with their machine guns ... they arrested a whole bunch of people, knocked people on the head, twisted women's arms around. They came down on people with their big guns and if it weren't for these lawyers that went up to them and said "We're lawyers, we're lawyers. Don't do anything to these people", they would have killed us. (Ferreira, 2004, pp. 358-359)

This narrative sits with quantitative research undertaken alongside 20 Yurok extended families with genealogy traced to the 1850 s and including 1,702 individuals, of which 544 were selected for the study. The findings highlighted that Yukon people who experience confinement in boarding schools, prison, foster homes, juvenile halls or who experience military trauma, sexual abuse or the trauma of the premature death of a close family member were more likely to "have a much higher probability of developing type 2 diabetes because of emotional suffering" (Ferreira, 2004, p. 358).

The impact of colonial oppression and historical trauma events create a "destablization process" within Native communities that impacts upon health and wellbeing (Walters \& Simoni, 2002; Walters, Simoni \& EvansCampbell, 2002). The embodiment of historical trauma response is also evidenced in the work by Walters and Simoni (2002), who highlight the impact of trauma and PTSD on Native women's health. They highlight that discrimination has been related not only to psychological and emotional distress but also is embodied 
through experiences of poor physical health and medical conditions such as high blood pressure. Furthermore, evidence indicates that multiple forms or experiences of discrimination may culminate in physical and mental health symptoms for Native people and people of colour (Walters \& Simoni, 2002). In a study related to the impact of trauma on the wellbeing of two-spirit people, Lehavot, Walters, and Simoni (2009) notes that higher levels of childhood trauma, physical assault, sexual assault and intimate partner violence was related with worse mental and physical health.

Historical trauma response within families has been engaged by Brave Heart and DeBruyn (1998) in the area of parenting, and EvansCampbell (2008) notes that the impact upon community includes the breakdown of traditional culture, values, rites of passage and knowledge about how to raise and parent children. Duran and Duran (1995) emphasize the colonial attack on the family through the boarding school system as being a process of eradicating the family from the thinking and practices of Native peoples and thereby removing a critical process of collective cultural reproduction through the generations. They argue that seeking to intervene with issues within Native families is made problematic as those issues are in fact "caused by a conspiracy that was implemented over a hundred years ago" (p. 28).

Historical trauma responses are multilevelled including individual, familial and community impacts, with transmission being at both personal and societal levels (EvansCampbell, 2008). However, much research has focused primarily upon individual impacts and has failed to engage the wider impacts that are intergenerational and collective. As such, Evans-Campbell (2008) argued that ensuring collective and societal impacts are actively engaged is an area that must be clearly developed in any Indigenous research in the area.

Whilst arguing the applicability of historical trauma theory, Estrada (2009) notes that more research is required with the Mexican/ Mexican American/Chicana/Chicano communities and raises points in regards to the complexity of historical events related to colonization and dispossession of lands and identity. Other examples that highlight the need to ensure specificity in regards to community are the studies undertaken in relation to both Native experiences (Duran \& Duran, 1995; Lehavot et al., 2009) and those of two-spirit communities (Lehavot et al., 2009; Walters et al., 2002; Walters \& Simoni, 2002). The assertion of the need to explore the impact of historical trauma theory is critical. It raises the issue that is central to this article in terms of the relevance of historical trauma to Māori research.

\section{Historical trauma theory in New Zealand}

Māori are grossly over-represented in New Zealand's trauma profiles. A 2005 study of 502 Māori showed that $65 \%$ of them had experienced one or more traumatic events over their lifetimes (Hirini, Flett, Long, \& Millar, 2005). In comparison with other groups, Māori are substantially more likely to experience the sudden loss of loved ones through hospitalization and premature death from a wide range of causes including cardiovascular disease, cancer, diabetes, asthma, infant mortality, self-harm, suicide, motor vehicle accidents, and unintentional and intentional injuries (Harris et al., 2006; Ministry of Health, 2010; Perinatal and Maternal Mortality Review Committee, 2010; Robson \& Harris, 2007).

In exploring the impact of historical trauma upon Māori it has become clear that the terminology associated with historical trauma theory is considered controversial in New Zealand. This is evidenced by extremely fervent reactions to Māori using the term "holocaust" in relation to colonization and traumatic events experienced by our tupuna (ancestors) (Turia, 
2000). Reaction to the use of the term by the then Associate Minister of Māori Affairs, Tariana Turia, was rapid and led to her being reprimanded by the then Prime Minister, Helen Clarke, who was quoted in the New Zealand Herald as follows:

"I know the [Waitangi] tribunal used it [holocaust] with respect to Taranaki. I do not agree with that and I do not want to see ministers using the term and causing offence again." And if that message were not clear enough, she reiterated it later on Monday: "I don't accept that the word holocaust can be validly used about the New Zealand experience." (Young, 2000, para. 13)

More recently the debate was reignited after a Waitangi Day Panel on Radio New Zealand, where Taranaki activist Keri Opai referred to the experiences of the invasion of the village of Parihaka as a form of holocaust, as is clearly noted in the Taranaki Report (Waitangi Tribunal, 1996). Again the response was rapid, this time from Stephen Goodman of the New Zealand Jewish Council. Goodman was reported as stating:

It is totally unacceptable for anyone to attempt associating European colonisation of New Zealand with the Holocaust. This is not the first time that Maori have trivialised the Holocaust by trying to associate it with their own perceived grievances. There is absolutely no valid comparison between the settlement of the country and the organised, state sponsored, genocide that was the Holocaust. As a language lecturer $\mathrm{Mr}$ Opai is obviously totally ignorant of world history; as an "academic" he should know better. His words are extremely offensive to the Jewish and other communities that were the target of the Shoah. ("Holocaust comparison”, 2012, paras. 4-5)

The significance of these responses to the use of terminology that is associated with historical trauma events is that they locate the ways in which discourse may create strong reactions within the wider non-Māori community. These debates illustrate a limited acknowledgement or recognition of the history of colonization and the severity of the traumatic acts perpetrated against Māori.

In order to utilize the framework of historical trauma theory within New Zealand there is a need to firstly understand that notions of genocide and ethnocide are valid in articulating analysis. Duran and Duran (1995) argue that understanding the central role of genocidal acts upon Indigenous peoples is critical. The comments made by Goodman ("Holocaust comparison", 2012) are a clear indication of the limited view given to what constitutes "state sponsored genocide". As such, it is important to have an overview of both the origins and the current definitional boundaries of the terms. Stein (1996) notes that the term "genocide", which was coined in 1933 by Raphael Lemkin, derives from the Greek term "genos" referring to "group" or "tribe", and the Latin term "cide" referring to "killing". Lemkin (1944) later published Axis Rule in Occupied Europe in which he discussed in detail the "exterminatory" practices of the Nazi regime. Huttenbach (2002) highlights that "at the heart" of genocidal acts is both the intent and act of seeking to exterminate groups of people.

Lemkin (1947) argued the need for international regulation of what he termed "genocide" and affirmation through the United Nations (UN) for a convention that affirmed genocide as a crime under international law (Huttenbach, 2002; Lemkin, 1947; Stein, 1996). The underpinning reasoning for such a move aligned to his belief that "the destruction of human groups is a problem of international concern ... such acts should be treated as crimes under the law of nations" (Lemkin, 1947, p. 146). This culminated in the development of the UN (1948) Convention on the Prevention and Punishment of the Crime of Genocide, which defines genocide as follows: 
Any of the following acts committed with intent to destroy, in whole or in part, a national, ethnical, racial or religious group, as such:

i. Killing members of the group;

ii. Causing serious bodily or mental harm to members of the group;

iii. Deliberately inflicting on the group conditions of life calculated to bring about its physical destruction in whole or in part;

iv. Imposing measures intended to prevent births within the group;

v. Forcibly transferring children of this group to another group. (p. 280)

Where it has been argued that the UN definition of genocide is broad, it does in fact align with the objectives that Lemkin (1947) identified as essential:

The crime of genocide involves a wide range of actions, including not only deprivation of life but also the prevention of life (abortions, sterilizations) and also devices considerably endangering life and health (artificial death in special camps, deliberate separation of families for depopulation purposes and so forth). All these actions are subordinated to the criminal intent to destroy or to cripple permanently a human group. The acts are directed against groups, as such, and individuals are selected for destruction only because they belong to these groups. In view of such a phenomenon the terms previously used to describe an attack upon nationhood were not adequate. Mass murder or extermination wouldn't apply in the case of sterilization because the victims were not murdered, rather a people was killed through delayed action by stopping propagation. Moreover mass murder does not convey the specific losses to civilization in the form of the cultural contributions which can be made only by groups of people united through national, racial or cultural characteristics. (p. 147)
Huttenbach (2002) states that the UN definition is more descriptive than conceptual. Kuper (1990) also highlights issues with definitions; however, he states that the UN definition of genocide as a crime is inclusive and clearly encompasses the experiences of Indigenous peoples. He argues that the definition is:

inclusive enough to encompass the genocides of colonization; the annihilation of indigenous groups; the destruction of stranger groups cast in the role of hostages to their host societies; the large scale massacres resulting from struggles for self-determination, separation or power; and the Holocaust and genocides in time of war. (p. 20)

Such definitions locate acts of colonial invasion and intentional acts that sought to annihilate or destroy Indigenous peoples as acts of genocide. This is the experience of Māori people, as exampled in the discussion by Keri Opai (as cited in Rilkoff, 2012) of the experiences of whānau, hapū and iwi in Taranaki and which is articulated in the Waitangi Tribunal (1996) as "the holocaust of Taranaki history and the denigration of the founding peoples in a continuum from 1840 to the present” (p. 312).

Establishing the relationship of acts of genocide and ethnocide to the history of colonization within New Zealand is important to understanding the possibilities of utilizing historical trauma theory within Māori research that explores the impact of trauma and oppression. Given historical events imposed upon Māori within New Zealand, there is clearly a need to explore more fully the ways in which such “cataclysmic events" (Brave Heart \& DeBruyn, 1998; Walters, 2007) impact upon the wellbeing of Māori. Māori have suffered high rates of trauma in the areas of sexual abuse, violence, imprisonment, child abuse, combat exposure veterans, mental health, land alienation and toxin exposures. Whilst there is a growing body of research on the socio-economic determinants of Māori health there is virtually no research in 
New Zealand on the intergenerational impacts of trauma on Māori and the impacts on Māori health outcomes as framed through a historical trauma lens.

\section{Conclusion}

This article has explored the significance of historical trauma theory and the relevance of such theory to Māori research. It is a theoretical framework that is being utilized alongside kaupapa Mãori theory-for example, in the Māori health research programme He Kokonga Whare: Māori Intergenerational Trauma and Healing-in the mode of what may be referred to as a theoretical hoa haere (ally) (Pohatu, 1996). As a hoa haere, historical trauma theory may be positioned as a theory that works alongside kaupapa Māori theory as a means by which to gain further understanding of the impact of acts of historical trauma imposed through colonization.

As a school of thought and emerging disciplines, historical and intergenerational trauma theories enable research to investigate Māori health, wellbeing and healing within a collective historical context that is particularly cognizant of specific Indigenous issues. This perspective enables us to understand the historic or intergenerational traumatic experience of, for example, veterans or victims of war, genocide and other forms of subjugation, discrimination or abuse including collective loss of land, language, culture and identity or integration, assimilation and segregation policies.

Within New Zealand, such findings signal frighteningly exponential impacts. For example, the Public Health Advisory Committee (2010) recently estimated that upwards of 20,000 primarily Māori children may be intergenerational victims of incarceration. Historical and intergenerational theory provides a historical context and framework for understanding traumatic experience. Drawing upon historical trauma theory enables Māori researchers to bring together Māori and Indigenous understandings in a way that enables us to explain and understand the complexities of Māori experiences of trauma and intergenerational transmission. This in turn enables the creation of space for further identifying pathways, factors and conditions which lead to intergenerational recovery and healing for our people. In order to engage fully with the impacts of colonization on Māori wellbeing we must reclaim the language that enables us to talk about those events and reveal fully the impact of historical trauma events and their contribution to the health disparities experienced by Māori whānau, hapū and iwi. Having historical trauma theory as a framework that walks alongside kaupapa Māori theory as a theoretical ally is one way by which to advance that intention.

\section{Acknowledgements}

We would like to acknowledge the many participants, researchers and programme colleagues that contributed towards this work under the He Kokonga Whare Research Programme. Funding was provided by the New Zealand Health Research Council (11/793).

\section{Glossary}

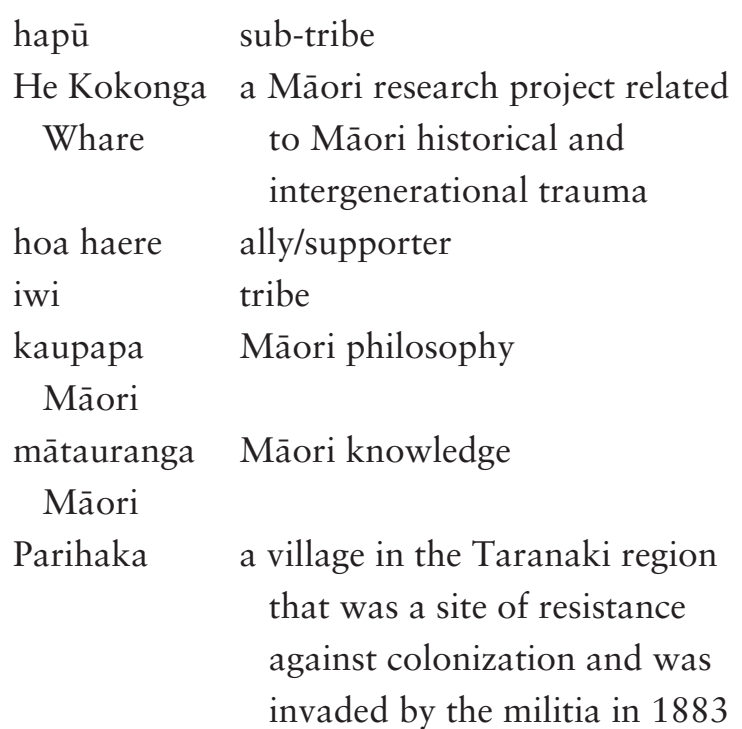




$\begin{array}{ll}\text { reo } & \text { language } \\ \text { tikanga } & \text { protocols } \\ \text { tupuna } & \text { ancestor } \\ \text { whakapapa } & \text { genealogy } \\ \text { whakataukī } & \text { proverb } \\ \text { whānau } & \text { extended family }\end{array}$

\section{References}

Balsam, K. F., Huang, B., Fieland, K. C., Simoni, J. M., Walters, K. L. (2004). Culture, trauma, and wellness: A comparison of heterosexual and lesbian, gay, bisexual, and two-spirit Native Americans. Cultural Diversity \& Ethnic Minority Psychology, 10(3), 287-301.

Brave Heart, M. Y. H. (1999). Gender differences in the historical trauma response among the Lakota. Journal of Health o Social Policy, 10(4), 1-21.

Brave Heart, M. Y. H. (2000). Wakiksuyapi: Carrying the historical trauma of the Lakota. Tulane Studies in Social Welfare, 21-22, 245-266.

Brave Heart, M. Y. H., \& DeBruyn, L. M. (1998). The American Indian holocaust: Healing historical unresolved grief. American Indian and Alaska Native Mental Health Research Journal, 8(2), 56-78.

Drinnan, R. (1987). Keeper of concentration camps: Dillion S. Myer and American racism. Berkeley, CA: University of California Press.

Duran, E. (2006). Healing the soul wound: Counseling with American Indians and other Native peoples. New York, NY: Teachers College Press.

Duran, E., \& Duran, B. (1995). Native American postcolonial psychology. Albany, NY: State University of New York Press.

Estrada, A. L. (2009). Mexican Americans and historical trauma theory: A theoretical perspective. Journal of Ethnicity in Substance Abuse, 8, 330-340.

Evans-Campbell, T. (2008). Historical trauma in American Indian/Native Alaska communities: A multilevel framework for exploring impacts on individuals, families, and communities. Journal of Interpersonal Violence, 23, 316-338.

Ferreira, M. L. (2004). Love in colonial light: History of Yurok emotions in Northern California. In M. Ferreira \& G. Lang (Eds.), Indigenous peoples and diabetes (pp. 357-385). Durham, NC: Carolina Academic Press.

Gagne, M. A. (1998). The role of dependency and colonialism in generating trauma in First Nations citizens: The James Bay Cree (pp. 355-372). In Y. Danieli (Ed.), The international handbook of multigenerational legacies of trauma. New York, NY: Plenum Press.

Harris, R., Tobias, M., Jeffreys, M., Waldegrave, K., Karlsen, S., \& Nazroo, J. (2006). Effects of self-reported racial discrimination and deprivation on Māori health and inequalities in New 
Zealand: Cross-sectional study. The Lancet, 367, 2005-2009.

Hirini, P., Flett, R., Long N., \& Millar, M. (2005). Frequency of traumatic events, physical and psychological health among Māori. New Zealand Journal of Psychology, 34(1), 20-27.

Holocaust comparison to NZ colonisation "unacceptable". (2012, 6 February). Tangatawhenua. com. Retrieved from http://news.tangatawhenua. com/archives/15787

Howard, J. (2008). Concentration camps on the home front: Japanese Americans in the house of Jim Crow. Chicago, IL: University of Chicago Press.

Huttenbach, H. R. (2002). From the editor: Towards a conceptual definition of genocide. Journal of Genocide Research, 4(2), 167-175.

Kuper, L. (1990). The genocidal state: An overview. In P. L. van den Berghe (Ed.), State violence and ethnicity (pp. 19-52). Niwot, CO: University Press of Colorado.

Lehavot, K., Walters, K. L., \& Simoni, J. M. (2009). Abuse, mastery, and health among lesbian, bisexual, and two-spirit American Indian and Alaska Native Women. Cultural Diversity and Ethnic Minority Psychology, 15(3), 275-284.

Lemkin, R. (1944). Axis rule in occupied Europe: Laws of occupation: Analysis of government: Proposals for redress. Washington, DC: Carnegie Endowment for International Peace.

Lemkin, R. (1947). Genocide as a crime under international law. American Journal of International Law, 41(1), 145-151.

Ministry of Health. (2010). Tatau kahukura: Māori health chart book 2010 (2nd ed.). Wellington, NZ: Author.

Nagata, D. K. (1991). Transgenerational impact of the Japanese-American internment: Clinical issues in working with children of former internees. Psychotherapy, 28(1), 121-128.

Perinatal and Maternal Mortality Review Committee. (2010). Perinatal and maternal mortality in New Zealand 2008: Fourth report to the Minister of Health, July 2009 to June 2010. Wellington, NZ: Ministry of Health.

Pihama, L. (2001). Tihei mauri ora, honouring our voices, Mana wahine as a kaupapa Māori theoretical framework (Unpublished doctoral dissertation). University of Auckland, Auckland, New Zealand.

Pohatu, T. (1996). I tiipu ai taatou i ngaa turi o o tatatau maatua tiipuna: Transmission and acquisition processes within kaawai whakapapa
(Unpublished master's thesis). University of Auckland, Auckland, New Zealand.

Public Health Advisory Committee. (2010). The best start in life: Achieving effective action on child health and wellbeing. Wellington, NZ: Ministry of Health.

Rilkoff, M. (2012, 6 February). Academic claims Maori holocaust. Stuff. Retrieved from http://www. stuff.co.nz/taranaki-daily-news/news/6370287/ Academic-claims-Maori-holocaust

Robson, B., \& Harris, R. (Eds.). (2007). Hauora: Màori standards of health IV. A study of the years 2000-2005. Wellington, NZ: Te Rōpū Rangahau Hauora a Eru Pōmare.

Stein, S. D. (1996). Genocide. In E. Cashmore (Ed.), Dictionary of race and ethnic relations (4th ed.). London, England: Routledge.

Taki, M. (1996). Kaupapa Māori and contemporary iwi resistance (Unpublished master's thesis). University of Auckland, Auckland, New Zealand.

Turia, T. (2000). Keynote address to the annual conference of the New Zealand Psychological Society. New Zealand Psychological Society, 99, 29-32.

United Nations. (1948). Convention on the prevention and punishment of the crime of genocide. Retrieved from https://treaties.un.org/doc/ Publication/UNTS/Volume\%2078/volume-78I-1021-English.pdf

Waitangi Tribunal. (1996). The Taranaki report: Kaupapa tuatahi, muru me te raupatu: The muru and raupatu of the Taranaki land and people. Wai 143. Wellington, NZ: Government Printer.

Walters, K. (2007). Presentation at the "Does Racism Make Us Sick?” Symposium, 13th Annual Summer Public Health Research Institute and Videoconference on Minority Health, University of North Carolina, Capitol Hill, North Carolina. Retrieved from http://www.minority.unc.edu/ institute/2007/

Walters, K., \& Simoni, J. (2002). Reconceptualizing Native women's health: An "indigenist” stresscoping model. American Journal of Public Health, 92(4), 520-524.

Walters, K. L., Beltran, R., Huh, D., \& Evans-Campbell, T. (2011). Dis-placement and dis-ease: Land, place and health among American Indians and Alaska Natives. Communities, Neighborhoods, and Health: Social Disparities in Health and Health Care, 1(Part 2), 163-199.

Walters, K. L., Simoni, J., \& Evans-Campbell, T. (2002). Substance use among American Indians and Alaska Natives: Incorporating culture in 
an "indigenist" stress-coping paradigm. Health Reports, 117, Supplement 1.

Walters K. L., \& Walters M. S. W. (1997). Urban lesbian and gay American Indian identity. Journal of Gay \& Lesbian Social Services, 6(2), 43-65.

Yellow Horse, S., \& Brave Heart, M. Y. H. (2005). The

Takini Network of Denver: A review of the literature: Healing the Wakanheja: Evidence based, promising, and culturally appropriate practices for American Indian/Alaska Native children with mental health needs. Wellbriety: White Bison's Online Magazine, 6(6). Retrieved from http:// www.whitebison.org/magazine/2005/volume6/ chapter3_NAC.pdf

Young, A. (2000, 6 September). Holocaust apology puts minister in hot water. New Zealand Herald. Retrieved from http://www.nzherald.co.nz/nz/ news/article.cfm?c_id=1\&objectid=150333 